\title{
Minority stress, depression, and cigarette smoking among Chinese gay versus bisexual men: A two- group structural equation model analyses
}

Jingjing Li ( $\square$ jingjing.li@emory.edu )

Emory University School of Public Health https://orcid.org/0000-0003-4652-3379

\section{Danqin Huang}

Wuhan University, School of Health Sciences

\section{Michael Windle}

Emory University School of Public Health

\section{Cam Escoffery}

Emory University School of Public Health

\section{Wei Wang}

Xuzhou Medical University

\section{Xiaoyan Li}

Wuhan University School of Health Sciences

Kevin Tao

Georgia Institute of Technology College of Engineering

\section{Regine Haardörfer}

Emory University School of Public Health

\section{Shiyue Li}

Wuhan University School of Health Sciences

\section{Carla J Berg}

George Washington University Milken Institute of Public Health

\section{Hong Yan}

Wuhan University School of Health Sciences

\section{Research article}

Keywords: Minority stress; depression; cigarette; smoking; gay men; bisexual men; China

Posted Date: November 26th, 2019

DOI: https://doi.org/10.21203/rs.2.17811/v1 
License: (c) (i) This work is licensed under a Creative Commons Attribution 4.0 International License. Read Full License

Version of Record: A version of this preprint was published at BMC Public Health on July 9th, 2021. See the published version at https://doi.org/10.1186/s12889-021-10888-5. 


\section{Abstract}

Background: Literature in the West suggested that bisexual men have a higher smoking rate compared to gay men. Data on patterns of smoking among gay and bisexual men are limited in Eastern countries like China. This study examined the cigarette smoking prevalence for gay versus bisexual men in China and their unique minority stress - smoking pathways. Methods: Between September 2017 and November 2018, we surveyed a convenience sample of 538 gay men and 138 bisexual men recruited from local sexual minority organizations in four metropolitan cities in China (i.e., Beijing, Wuhan, Nanchang, and Changsha). Measures included sexual orientation, sociodemographics, theory-based minority stressors, depressive symptoms, and past 30-day cigarette smoking. Two-group (gay men vs. bisexual men) structural equation modeling (SEM) was used to test possible distinct mechanisms between theory-based stressors, depressive symptoms, and cigarette smoking among gay men and bisexual men, respectively. Results: The average age of participants was 26.51 (SD $=8.41$ ) years old and $76.3 \%$ of them had at least a college degree. Bisexual men reported a higher rate of cigarette smoking compared to gay men $(39.9 \%$ vs. $27.3 \%$ ). Two-group SEM indicated that the pathways for cigarette smoking were not different between gay and bisexual men. Higher rejection anticipation was associated with greater depressive symptoms (standardized $\beta=0.32, p<.001$ ), and depressive symptoms was not associated with cigarette smoking. Conclusions: Minority stress, specifically rejection anticipation, may be critical considerations in addressing depressive symptoms, but not smoking, among both gay and bisexual men in China.

\section{Background}

China has one of the highest burden of smoking in the world. ${ }^{[1]}$ Each year, approximately 1,000,000 people in China die prematurely from smoking-related diseases. ${ }^{[2,3]}$ Data from Western countries have largely indicated higher rates of cigarette smoking among sexual minorities compared to the general population. ${ }^{[4-10]}$ While the literature regarding smoking among sexual minorities in Eastern countries like China is limited, some studies have similarly shown increased smoking prevalence in this population. For example, a study of gay and bisexual men in Shanghai, China indicated a cigarette smoking prevalence of $66 \%,{ }^{[11,12]}$ approximately $15 \%$ higher than the national average and $22 \%-33 \%$ higher than the city-level prevalence. ${ }^{[13]}$

Minority Stress Theory $(1995 ; 2003)$ suggests that minority stress can exacerbate mental health problems and consequently lead to increased health risk behaviors. ${ }^{[14,15]}$ Empirically, numerous studies have shown that these minority stressors are positively associated with psychological distress and health risk behaviors such as smoking. ${ }^{[7,16-20]}$ However, not all sexual minorities experience the same stress or related health risks. Studies conducted in Western countries indicate that bisexuals are at increased risk for mental health problems and substance use compared to monosexuals (i.e., gay/lesbians and heterosexuals). ${ }^{[21,22]}$ Such intergroup differences between bisexuals and monosexuals might be explained by greater minority stress experienced by bisexuals. For instance, Sweet and Welles (2012) 
suggest that, compared to gay men, bisexual men may experience significantly more adverse childhood experiences. ${ }^{[23]}$

Although few studies in China have explicitly examined the mechanism between minority stress and cigarette use, qualitative research suggests that Chinese sexual minority men may use substances to relieve the stress of hostile social stigma, as well as familial and cultural pressures. ${ }^{[24]}$ Additionally, it is unclear whether significant heterogeneity exists between bisexuals and monosexuals regarding their minority stress experiences and related health risks, particularly between Chinese gay men and bisexual men. This study aimed to contribute to the literature by examining the prevalence of cigarette smoking in a sample of Chinese gay and bisexual men and distinctive underlying mechanisms of cigarette smoking between these subgroups, specifically the unique minority stress - smoking pathways, using two-group (gay vs. bisexual men) structural equation modeling (SEM).

\section{Methods}

\section{Study Population and Data Collection}

Between September 2017 and January 2018, baseline survey data of 755 self-identified gay and bisexual men from a three-year cohort study examining health risk behaviors among Chinese gay/bisexual men were collected using venue-based sampling from college campus-based sexual minority-serving organizations in four metropolitan cities in China (i.e., Beijing, Wuhan, Nanchang, and Changsha). After screening for eligibility (self-identified as gay/bisexual men and aged 16 years or older), participants were given a brief explanation of the survey's purpose. Informed consent was obtained from every participant. Each participant received a one-time compensation of 50 Chinese RMB (approximately $\$ 8$ US dollars) for their time. For this study, we excluded 79 (10.5\%) participants who reported "heterosexual/unsure/other" sexual orientation. Participants with "HIV-positive" status were also excluded as patients on medical therapies might have very different smoking patterns and might confound findings from current study. The analytical sample size for this study was 676 . This study was approved by the Institutional Review Board (IRB) at [blinded for review].

\section{Measures}

Primary outcome: Cigarette smoking. Participants were asked, "During the past 30 days, on how many days did you smoke cigarettes? Little cigars or cigarillos? Traditional pipe? Chewing tobacco? Ecigarettes? Hookah?" Given that fewer than 10 participants reported on alternative tobacco use (i.e., little cigars or cigarillos, traditional pipe, chewing tobacco, e-cigarette, and hookah), this study only focused on the past 30-day cigarette smoking outcome, dichotomized as "no" versus "any smoking."

Primary grouping variable: Sexual orientation. Sexual orientation was assessed by asking, "Is your sexual orientation: heterosexual; gay or homosexual; bisexual; or unsure?" All responses were coded dichotomously $(0=$ gay and $1=$ bisexual). Responses with "unsure" were excluded. 
Sociodemographic characteristics. Participants were asked to provide sociodemographic information, including age, education (high school/below vs. college/above), place of origin (urban vs. rural), employment (dummy coded into student, employed, and unemployed), marital status (unmarried/divorced vs. married), monthly income ( $\leq 3000$ RMB [73 USD] vs. $>3000$ RMB), and nature of their health insurance (yes vs. no/unsure).

Depressive symptoms as mediator. Depressive symptoms were hypothesized as a mediator of the relationships between minority stressors and cigarette smoking (Figure 1) and were assessed with the Center for Epidemiological Studies Depression (CES-D) scale. ${ }^{[25]}$ The CES-D is a 20-item scale designed to measure depressive symptoms experienced by the individual within the past week. Items were answered on a 4-point scale ranging from $0=$ less than a day or never to $3=5-7$ days. The Cronbach's alpha was 0.89 .

Minority Stressors. Informed by Minority Stress Theory, ${ }^{[26,27]}$ we measured distal minority stressors (everyday discrimination), proximal minority stressors (outness, rejection anticipation, identity concealment, and internalized homophobia), general stressors (adverse childhood experiences), and stress-moderating factors (social support and resilience).

Everyday discrimination was assessed using the Everyday Discrimination Scale. ${ }^{[28]}$ This scale asks about the frequency of 9 types of hassles and prejudice events that sexual minority people may encounter. This 9-item scale is rated on a 6-point Likert scale with response options of $1=$ happens daily to $6=$ never happened. All responses were reverse coded and averaged to create a mean score, with higher scores indicating severer everyday discrimination. The Cronbach's alpha coefficient was 0.94 for this scale.

Outness was assessed by asking respondents "Have you ever 'come out' to anyone?" All responses were coded dichotomously $(0=n o$ and $1=y e s)$.

Rejection anticipation was assessed with a scale which was originally used to assess stigma of mental illness. ${ }^{[29]}$ Later, this scale was modified and adapted by Forst et al. (2015) for assessing sexual minority's state of hypervigilance and worry about being rejected. ${ }^{[17]}$ This 6-item scale is rated on a 5point Likert scale, ranging from $1=$ applies very strongly to $5=$ does not apply at all. All responses were reverse coded and averaged to create a mean score, with higher scores indicating higher expectation of rejection. The Cronbach's alpha of this scale in this study was 0.88 .

Identity concealment was assessed using a subscale on nondisclosure developed and validated by Testa et al.(2015). ${ }^{[30]}$ This 6-item scale asks about the intentions and behaviors of sexual minority individuals to avoid disclose their sexual minority identities. This scale is rated on a 5-point Likert scale, ranging from $1=$ applies very strongly to $5=$ does not apply at all. All responses were reverse coded and averaged to create a mean score, with higher scores indicating greater identity concealment. The Cronbach's alpha was 0.91 . 
Internalized homophobia was assessed using the Internalized Homophobia Scale which was originally developed by Martin and Dean (1987) ${ }^{[31]}$ and further modified and validated by Forst et al. (2009; 2015). $[17,32]$ This scale asks about the negative attitudes sexual minorities hold against their own sexual identities. This 8-item scale is rated on a 4-point Likert scale, ranging from 1=never to $4=a /$ ways. Responses were averaged to create a mean score, with higher scores indicating greater internal homophobia. The Cronbach's alpha was 0.89 .

Adverse childhood experiences (ACES) was assessed using a 10-item ACEs index developed by the U.S. Centers for Disease Control and Prevention. ${ }^{[33,34]}$ This index asks about the physical and mental abuse and traumatic experiences of participants prior to 18 years old. Participants answered $0=n o$ or $1=y e s$ to each item. Total score of all responses was summed; higher scores indicate more ACEs. The Cronbach's alpha was 0.63 .

Social support was assessed with the Multidimensional Scale of Perceived Social Support, ${ }^{[35]}$ which measures perceived support from family, friends, and significant others. This 12-item scale is rated on a 7-point Likert scale, ranging from 1=very strongly disagree to $7=$ very strongly agree. The total score of this scale was calculated for each participant, with higher scores indicating more social support. The Cronbach's alpha was 0.94 .

Resilience was assessed with the 10-item Connor-Davidson Resilience scale. ${ }^{[36,37]}$ This scale is a measure of stress coping capabilities. It is rated on a 5-point Likert scale ranging from $1=$ not true at all true to $5=$ true nearly all of the time. The responses are summed to derive a total score, with higher scores indicating more resilience. The Cronbach's alpha was 0.95 .

\section{Statistical Analysis}

Univariate analyses were conducted to examine the distribution of each variable. ANOVA and chi-square tests were conducted to assess the bivariate relationships between sociodemographic and psychosocial variables and the cigarette smoking outcome. We also examined the multi-collinearity between all variables. In consideration of study power, we excluded selected sociodemographic variables (i.e., education, marriage, monthly income, and health insurance) from the modeling analyses, as these variables either were not associated with the outcome or showed considerable collinearity (data not shown).

For the two-group SEM, we specified the SEM model in Figure 2 based on Minority Stress Theory, preliminary analyses, and correlation matrix results. A two-phase modeling approach was used for the two-group SEM. ${ }^{[38]}$ First, we examined measurement invariance (i.e., item-scale relationships) between gay and bisexual participants using confirmatory factor analysis (CFA). Second, we examined structural invariance (i.e., hypothesized relationships among variables) between gay and bisexual participants. Chi- 
square differences between these two models were examined and indicated non-significant results and thus no group differences in the measurement models. ${ }^{[39]}$

Then, we examined the model fit and path-coefficients of the final two-group structural SEM. The model fit indices included: chi-square test, standardized root mean square residual (SRMR), comparative fit index (CFI), Tucker-Lewis fit index (TLI), the root mean-square error of approximation (RMSEA), and weighted root mean square residual (WRMR). The indicators of goodness of fit were: $\chi 2 p<0.05$; SRMR > $0.08 ; \mathrm{CFI}>0.90 ; \mathrm{TLI}>0.90 ; \mathrm{RMSEA}<0.05$; and WRMR $<1 .{ }^{[40]}$ The bootstrapping method was used to test $95 \%$ Confidence Interval $(95 \% \mathrm{Cl})$. Standardized regression $(\beta)$ coefficients, the standard errors, and $\mathrm{p}$ values for $\beta$ were reported in the final model.

Data were double-entered and cleaned using EpiData 3.1 (The EpiData Association, Odense, Denmark) software. Descriptive analysis and sequential regressions were conducted using SAS 9.4 (SAS Institute Inc.: Cary, NC, USA). Two-group SEM was conducted using Mplus 8.0 (Muthén \& Muthén: Los Angeles, CA, USA).

\section{Results}

\section{Descriptive Statistics}

Table 1 shows that, among the full sample, the proportion of cigarette use was $29.9 \%$. The average age of the participants was 26.51 ( $S D=8.41$ ) years old, $76.3 \%$ reported holding college degree or above, $31.5 \%$ were current students, and $58.6 \%$ were employed. Bisexual men reported a higher rate of cigarette smoking compared to gay men (39.9\% vs. $27.3 \%)$. Rejection anticipation was significantly associated with cigarette smoking. Because marriage and health insurance were not associated with cigarette smoking, these variables were excluded from subsequent modeling analyses. Because education and monthly income correlated with employment, we included employment but excluded education and monthly income in the subsequent modeling.

\section{Correlation Statistics}

The correlation matrix examining group differences between gays and bisexuals (Table 2) indicated that employment was the only significant correlate of cigarette smoking in both gay and bisexual subgroups. Among all psychosocial factors, group differences were only found regarding rejection anticipation and depressive symptoms. Thus, the two-group SEM included rejection anticipation, depressive symptoms, and cigarette smoking, predicted by employment (dummy coded as student or employed) (Figure 2).

\section{Two-Group SEM}

Measurement model. We constructed unconstrained and constrained measurement CFA models. According to the model fit indices for the unconstrained model $(X 2=1326.7$ (576), $p<.001$; RMSEA $=.061$; $\mathrm{CFI}=.908 ; \mathrm{TLI}=.896 ; \mathrm{SRMR}=.056)$ and factor-loading constrained model $(\chi 2=1358.2(600), p<.001 ;$ 
RMSEA $=.061 ; \mathrm{CFI}=.907 ; \mathrm{TLI}=.900 ; \mathrm{SRMR}=.061)$, the chi-square difference test $(\chi 2=31.5[24])$ was non-significant, indicating factor loading invariance. Therefore, we moved on to the structural analysis using this invariant measurement model.

Structural model. According to the model fit indices for the unconstrained model $(\chi 2=971.0$ (761), $p<.001$; RMSEA $=.029 ; \mathrm{CFI}=.920 ; \mathrm{TLI}=.916 ; \mathrm{WRMR}=1.312)$ and constrained model $(\chi 2=981.3(770), \mathrm{p}<.001$; RMSEA $=.028 ; \mathrm{CFI}=.920 ; \mathrm{TLI}=.916 ; \mathrm{WRMR}=1.397)$, the chi-square difference test $(X 2=10.3[9])$ was non-significant, indicating structural invariance for gay and bisexual samples. The final two-group SEM fits the data well.

Final modeling results. For both gay and bisexual men (Figure 3), rejection anticipation was positively associated with greater depressive symptoms (standardized $\beta=0.30, p<.001$ ) and negatively associated with being a current cigarette smoker (standardized $\beta=-0.15, p<.001$ ). Being a student was positively associated with higher rejection anticipation (standardized $\beta=0.17, p<.05$ ) and was negatively associated with cigarette smoking (standardized $\beta=-0.33, p<.05$ ). Being a student was not associated with depressive symptoms. Depressive symptoms not associated with cigarette smoking.

\section{Discussion}

This study examined cigarette smoking among sexual minority men in China through the lens of the Minority Stress Theory. Our findings showed that bisexual men reported a higher rate of cigarette smoking compared to gay men $(39.9 \%$ vs. $27.3 \%)$ in China. This is similar to studies in the West that bisexuals often report higher use of substances compared to monosexuals. ${ }^{21,22]}$

Minority stress, particularly rejection anticipation, was positively associated with depressive symptoms in both gay and bisexual subgroups. This finding is consistent with studies suggesting that rejection anticipation is associated with the onset of depressive symptoms. ${ }^{[41,42]}$ Culturally, Chinese society highly values the sense of belonging to the "majority". In Chinese culture, being a majority represents righteousness and power, whereas minorities may be marginalized and/or ostracized. ${ }^{[43]}$ Rejection anticipation was reversely associated with cigarette smoking. This unexpected result might be influenced by the launch of public smoke-free legislation in major cities like Beijing since 2014, that participants who anticipated rejections based on their sexual minority orientations might tend to minimize other types of rejections from the society including smoking. Taken together, rejection anticipation is a critical construct for sexual minority stress that might predict important mental health outcomes, especially in a collective culture like China.

No direct relationship between depression and cigarette smoking among gay and bisexual men was indicated. However, other research has documented significant relationships between mental distress and smoking among sexual minority men globally. ${ }^{[44-47]}$ There might be some contextual factors - such as tobacco-free policy in our campus-based venues, peer influences, and social or cultural norms confounding or buffering the effect of minority stressors on cigarette use in this study population. For 
example, structural discrimination was found to be a significant predictor of smoking among sexual minority subgroup. ${ }^{[48]}$ Peer violence and pressure also could lead to tobacco use among sexual minority youth. ${ }^{[49]}$ Future studies should consider the contextual influencing factors to better understand the effects of minority stressors on cigarette smoking.

We did not find distinctive inter-group differences between subgroups in the mechanism through which minority stress might affect cigarette smoking. According to a Chinese qualitative study on bisexuality, bisexual identity is a fairly new concept for many Chinese, especially among young adults and students, and bisexual individuals might undergo long time exploration of sexual identity and might experience enormous confusion and social pressure. ${ }^{[50]}$ It may be that some young participants or student participants in our study might still be exploring their identities and assume themselves to be gay, bisexual, or heterosexual, depending on the sex of their current partners. ${ }^{[22]}$ Thus, the distinction between gay men and bisexual men might be biased because of high proportion of students in our study. More studies are needed to explain why bisexual men experienced higher cigarette smoking in China.

Results indicated that being a student was positively associated with rejection anticipation among Chinese sexual minority men. In the U.S., sexual minority students experience higher rates of parental or peer rejections compared to heterosexual counterparts. ${ }^{[51]}$ Moreover, $86.2 \%$ of U.S. sexual minority students experienced verbal harassment and $44.1 \%$ of these students experienced physical harassment. ${ }^{[52]}$ In the U.S., sexual minority students felt less safe at school compared to heterosexual students. ${ }^{[53]}$ Depending on the school climate, sexual minority students might be experiencing in a hostile or protective environment. Currently, no known study has evaluated the impact of school environments or policies on the health of sexual minority students in China. Although we did not find significant associations between being a student and depression, more studies are needed to evaluate the impact of school setting toward their feeling of rejection, mental illness, and health risk behaviors among Chinese sexual minority students.

\section{Limitations}

We collected data from convenience sample that was mainly comprised of urban, well-educated, and high-income gay/bisexual men, which might not be representative to all sexual minority men. Also, the data were collected in sexual minority-serving organizations located in or close to college campuses, thus our measurement of cigarette smoking might be influenced by the smoke-free campus policies enforced since 2014 and therefore might not reflect the actual cigarette smoking prevalence. The cross-sectional nature of the data limits the causal inference regarding our findings. Due to the page limitation of the survey instrument, we did not assess important factors that might influence smoking behaviors such as cultural aspects or peers or family influences. Last, data were collected based on self-report using penand-paper and thus might be prone to recall bias and social desirability.

\section{Conclusions}


Guided by Minority Stress Theory, this study is among the first to examine the minority stress - cigarette use pathway among a sample of Chinese gay and bisexual men. Our findings showed that bisexual men are more likely to smoke cigarette compared to gay men. Minority stress, particularly rejection anticipation, was associated with depressive symptoms in both gay and bisexual men, but depressive symptoms were not associated with cigarette smoking. Although Minority Stress Theory did not provide a framework for understanding mechanisms underlying the heightened cigarette smoking among bisexual men compared to gay men within our sample of sexual minority men in China, attending to the intergroup differences within sexual minorities related distinct sexual minority stress and cigarette smoking patterns remains an important area for producing tailored and targeted intervention among sexual minorities in China and beyond.

\section{List Of Abbreviations}

SEM: structural equation modeling

SD: standard deviation

OR: Odd Ratio

Cl: Confidence Interval

CES-D: Center for Epidemiological Studies Depression Scale

ACEs: Adverse childhood experiences

ANOVA: Analysis of variance

CFA: confirmatory factor analysis

SRMR: standardized root mean square residual

CFI: comparative fit index

TLI: Tucker-Lewis fit index

RMSEA: the root mean-square error of approximation

WRMR: weighted root mean square residual

\section{Declarations}

\section{Ethics approval and consent to participate}

Our project was approved by the [deleted for blind review] Institutional Review Boards. All participants provide consent prior to completing the survey. 


\section{Consent to publish}

Not applicable because there is no identifiable images, videos, or details relating to an individual person in our manuscript.

\section{Availability of data and materials}

The datasets used and/or analyzed during the current study are available from the corresponding author (Dr. Hong Yan) on reasonable request.

\section{Competing interests}

All authors declare no competing interests.

\section{Funding}

This research is supported by the [deleted for blind review], [deleted for blind review], and [deleted for blind review].

\section{Authors' contributions}

Jingjing Li conceptualized the study, performed data analysis, and wrote the manuscript. Danqing Huang and Kevin Tao contributed to the manuscript writing and manuscript review. Michael Windle and Regine Haardörfer contributed to the conceptualization of the study and oversaw data analytical methods. Cam Escoffery reviewed data analytical methods and contributed to manuscript writing. Wei Wang, Xiaoyan Li, Shiyue Li, and Hong Yan collected the data. Carla J. Berg, Hong Yan, and Shiyue Li reviewed data analytical methods and contributed to manuscript writing.

\section{References}

1. WHO report on the global tobacco epidemic, 2017 [https://www.who.int/tobacco/surveillance/policy/country_profile/chn.pdf?ua=1]

2. Hu SS: Tobacco product use among adults-United States, 2013-2014. MMWR Morbidity and Mortality Weekly Report 2016, 65.

3. Chen ZM, Peto R, lona A, Guo Y, Chen YP, Bian Z, Yang L, Zhang WY, Lu F, Chen JS: Emerging tobacco-related cancer risks in China: A nationwide, prospective study of $\mathbf{0 . 5}$ million adults. Cancer 2015, 121(S17):3097-3106.

4. Wheldon CW, Kaufman AR, Kasza KA, Moser RP: Tobacco Use Among Adults by Sexual Orientation: Findings from the Population Assessment of Tobacco and Health Study. Lgbt Health 2018, 5(1):3344.

5. Baskerville NB, Dash D, Shuh A, Wong K, Abramowicz A, Yessis J, Kennedy RD: Tobacco use cessation interventions for lesbian, gay, bisexual, transgender and queer youth and young adults: A 
scoping review. Preventive medicine reports 2017, 6:53-62.

6. Berger I, Mooney-Somers J: Smoking cessation programs for lesbian, gay, bisexual, transgender, and intersex people: a content-based systematic review. Nicotine Tob Res 2016, 19(12):1408-1417.

7. Goldbach JT, Tanner-Smith EE, Bagwell M, Dunlap S: Minority Stress and Substance Use in Sexual Minority Adolescents: A Meta-analysis. Prev Sci 2014, 15(3):350-363.

8. Blosnich J, Lee JG, Horn K: A systematic review of the aetiology of tobacco disparities for sexual minorities. Tob Control 2013, 22(2):66-73.

9. Lee JG, Griffin GK, Melvin CL: Tobacco use among sexual minorities in the USA, 1987 to May 2007: a systematic review. Tob Control 2009, 18(4):275-282.

10. Schauer GL, Berg CJ, Bryant LO: Sex differences in psychosocial correlates of concurrent substance use among heterosexual, homosexual and bisexual college students. The American journal of drug and alcohol abuse 2013, 39(4):252-258.

11. Yu F, Nehl EJ, Zheng T, He N, Berg CJ, Lemieux AF, Lin L, Tran A, Sullivan PS, Wong FY: A syndemic including cigarette smoking and sexual risk behaviors among a sample of MSM in Shanghai, China. Drug Alcohol Depen 2013, 132(1-2):265-270.

12. Berg CJ, Nehl EJ, Wong FY, He N, Huang ZJ, Ahluwalia JS, Zheng T: Prevalence and Correlates of Tobacco Use Among a Sample of MSM in Shanghai, China. Nicotine Tob Res 2011, 13(1):29-35.

13. China CDC: Report of China City Adult Tobacco Survey 2013-14: A 14-city experience. In. UK: WHO; 2015.

14. Fluharty M, Taylor AE, Grabski M, Munafò MR: The association of cigarette smoking with depression and anxiety: a systematic review. Nicotine Tob Res 2016, 19(1):3-13.

15. Ziedonis D, Hitsman B, Beckham JC, Zvolensky M, Adler LE, Audrain-McGovern J, Breslau N, Brown RA, George TP, Williams J: Tobacco use and cessation in psychiatric disorders: National Institute of Mental Health report. In.: Society for Research on Nicotine and Tobacco; 2008.

16. Gamarel KE, Mereish EH, Manning D, Iwamoto M, Operario D, Nemoto T: Minority Stress, Smoking Patterns, and Cessation Attempts: Findings From a Community-Sample of Transgender Women in the San Francisco Bay Area. Nicotine Tob Res 2016, 18(3):306-313.

17. Frost $\mathrm{DM}$, Lehavot $\mathrm{K}$, Meyer $\mathrm{IH}$ : Minority stress and physical health among sexual minority individuals. Journal of behavioral medicine 2015, 38(1):1-8.

18. Wong CF, Schrager SM, Holloway IW, Meyer IH, Kipke MD: Minority stress experiences and psychological well-being: The impact of support from and connection to social networks within the Los Angeles house and ball communities. Prev Sci 2014, 15(1):44-55.

19. Lehavot K: Minority stress, coping, and health among sexual minority women. US: ProQuest Information \& Learning; 2012.

20. Hamilton CJ, Mahalik JR: Minority Stress, Masculinity, and Social Norms Predicting Gay Men's Health Risk Behaviors. J Couns Psycho/ 2009, 56(1):132-141. 
21. Ia Roi C, Meyer IH, Frost DM: Differences in sexual identity dimensions between bisexual and other sexual minority individuals: Implications for minority stress and mental health. American Journal of Orthopsychiatry 2019, 89(1):40.

22. Feinstein BA, Dyar C: Bisexuality, minority stress, and health. Current sexual health reports 2017, 9(1):42-49.

23. Walters M, Chen, JT., Breiding, MJ.,: The National Intimate Partner and Sexual Violence Survey (NISVS): 2010 Findings on Victimization by Sexual Orientation. In. Atlanta, GA: National Center for Injury Prevention and Control, Centers for Disease Control and Prevention;; 2013.

24. He N, Wong FY, Huang ZJ, Thompson EE, Fu C: Substance use and HIV risks among male heterosexual and 'money boy' migrants in Shanghai, China. Aids Care-Psychological and SocioMedical Aspects of Aids/Hiv 2007, 19(1):109-115.

25. Radloff LS: The CES-D scale: a self-report depression scale for research in the general population. Applied psychological measurement 1977, 1(3):385-401.

26. Meyer IH: Prejudice, social stress, and mental health in lesbian, gay, and bisexual populations: conceptual issues and research evidence. Psychol Bull 2003, 129(5):674.

27. Meyer IH: Minority stress and mental health in gay men. Journal of health and social behavior 1995:38-56.

28. Gonzales KL, Noonan C, Goins RT, Henderson WG, Beals J, Manson SM, Acton KJ, Roubideaux Y: Assessing the Everyday Discrimination Scale among American Indians and Alaska Natives. Psychological assessment 2016, 28(1):51.

29. Link BG: Understanding labeling effects in the area of mental disorders: An assessment of the effects of expectations of rejection. Am Sociol Rev 1987:96-112.

30. Testa RJ, Habarth J, Peta J, Balsam K, Bockting W: Development of the gender minority stress and resilience measure. Psychology of Sexual Orientation and Gender Diversity 2015, 2(1):65.

31. Martin JL, Dean L: Summary of measures: Mental health effects of AIDS on at-risk homosexual men. Unpublished manuscript 1987.

32. Frost DM, Meyer IH: Internalized homophobia and relationship quality among lesbians, gay men, and bisexuals. J Couns Psychol 2009, 56(1):97.

33. Felitti VJ, Anda RF, Nordenberg D, Williamson DF, Spitz AM, Edwards V, Marks JS: Relationship of childhood abuse and household dysfunction to many of the leading causes of death in adults: The Adverse Childhood Experiences (ACE) Study. American journal of preventive medicine 1998, 14(4):245-258.

34. Prevalence of individual adverse childhood experiences [www.cdc.gov/violenceprevention/acestudy/prevalence.html]

35. Tonsing K, Zimet GD, Tse S: Assessing social support among South Asians: The multidimensional scale of perceived social support. Asian journal of psychiatry 2012, 5(2):164-168. 
36. Campbell-Sills L, Stein MB: Psychometric analysis and refinement of the connor-davidson resilience scale (CD-RISC): Validation of a 10-item measure of resilience. Journal of Traumatic Stress: Official Publication of The International Society for Traumatic Stress Studies 2007, 20(6):1019-1028.

37. Connor KM, Davidson JR: Development of a new resilience scale: The Connor-Davidson resilience scale (CD-RISC). Depression and anxiety 2003, 18(2):76-82.

38. Kline RB: Principles and practice of structural equation modeling: Guilford publications; 2015.

39. Thompson B: Exploratory and confirmatory factor analysis: Understanding concepts and applications. Applied Psychological Measurement 2007, 31(3):245-248.

40. Hu Lt, Bentler PM: Cutoff criteria for fit indexes in covariance structure analysis: Conventional criteria versus new alternatives. Structural equation modeling: a multidisciplinary journal 1999, 6(1):1-55.

41. Normansell KM, Wisco BE: Negative interpretation bias as a mechanism of the relationship between rejection sensitivity and depressive symptoms. Cognition and Emotion 2017, 31(5):950-962.

42. Slavich GM, Thornton T, Torres LD, Monroe SM, Gotlib IH: Targeted rejection predicts hastened onset of major depression. Journal of social and clinical psychology 2009, 28(2):223-243.

43. Li Y: Li Yihen Self Selections: Sex, Love, Marriage and Other Issues. In.: Hohhot: Inner Mongolia University Press; 2006.

44. Xu W, Zheng L, Xu Y, Zheng Y: Internalized homophobia, mental health, sexual behaviors, and outness of gay/bisexual men from Southwest China. International journal for equity in health 2017 , 16(1):36.

45. Choi K-H, Steward WT, Miège P, Hudes E, Gregorich SE: Sexual Stigma, Coping Styles, and Psychological Distress: A Longitudinal Study of Men Who Have Sex With Men in Beijing, China. Arch Sex Behav 2015:1-9.

46. Pachankis JE, Hatzenbuehler ML, Starks TJ: The influence of structural stigma and rejection sensitivity on young sexual minority men's daily tobacco and alcohol use. Soc Sci Med 2014, 103:6775 .

47. Blosnich JR, Horn K: Associations of discrimination and violence with smoking among emerging adults: differences by gender and sexual orientation. Nicotine Tob Res 2011, 13(12):1284-1295.

48. Shires DA, Jaffee KD: Structural Discrimination is Associated With Smoking Status Among a National Sample of Transgender Individuals. Nicotine Tob Res 2016, 18(6):1502-1508.

49. Rosario M, Corliss HL, Everett BG, Russell ST, Buchting FO, Birkett MA: Mediation by peer violence victimization of sexual orientation disparities in cancer-related tobacco, alcohol, and sexual risk behaviors: Pooled youth risk behavior surveys. Am J Public Health 2014, 104(6):1113-1123.

50. Dong Wang: Bisexual identity: An in-depth interview [In Chinese]. Nanjing, China: Nanjing Normal University; 2013.

51. Ryan C, Huebner D, Diaz RM, Sanchez J: Family rejection as a predictor of negative health outcomes in white and Latino lesbian, gay, and bisexual young adults. Pediatrics 2009, 123(1):346. 
52. Kosciw JG, Diaz EM: Involved, Invisible, Ignored: The Experiences of Lesbian, Gay, Bisexual and Transgender Parents and Their Children in Our Nation's K-12 Schools: ERIC; 2008.

53. Institute of Medicine: The Health of Lesbian, Gay, Bisexual, and Transgender People: Building a Foundation for Better Understanding. In. Washington, DC: National Academies Press; 2011.

\section{Tables}

Table 1. Descriptive characteristics and bivariate analyses examining differences between past 30-day cigarette smoking $(\mathrm{N}=202)$ vs. non-smoking $(\mathrm{N}=474)$ in Chinese gay and bisexual men $(\mathrm{N}=676)$ 


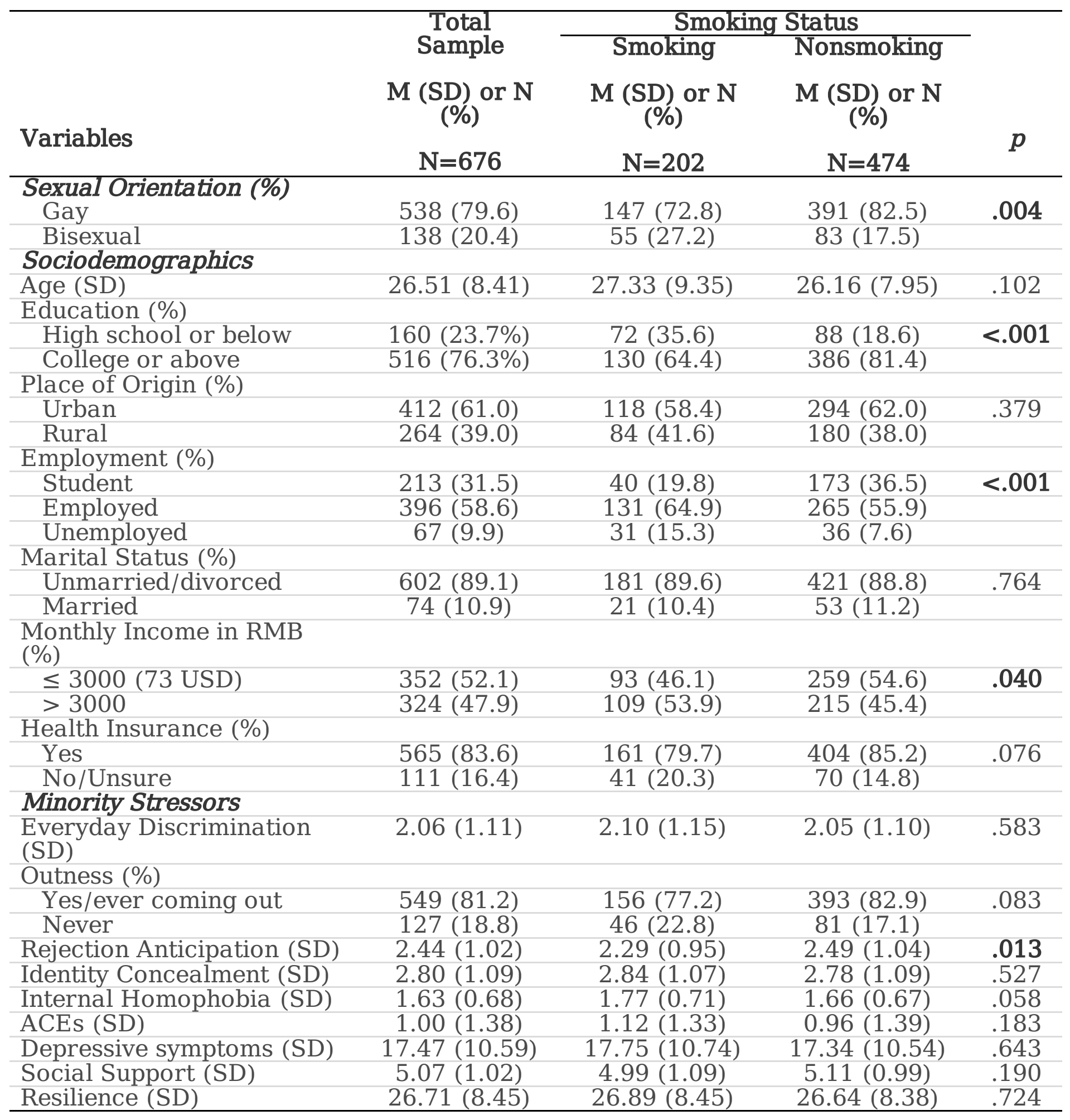

Table 2. Correlation matrix examining correlates of past 30-day cigarettes smoking among the full sample of Chinese sexual minority men, gays, and bisexuals, respectively 


\begin{tabular}{|c|c|c|c|}
\hline & $\begin{array}{c}\text { Total sample } \\
\text { r coefficient, } \\
\text { p value }\end{array}$ & $\begin{array}{c}\text { Gay } \\
\text { r coefficient, } \\
p \text { value }\end{array}$ & $\begin{array}{c}\text { Bisexual } \\
\text { r coefficient, } \\
p \text { value }\end{array}$ \\
\hline Variables & $\mathrm{N}=676$ & $\mathrm{~N}=538$ & $\mathbf{N}=138$ \\
\hline $\begin{array}{l}\text { Sociodemographics } \\
\text { Age }\end{array}$ & 0.063 & 0.061 & -0.005 \\
\hline Place of Origin & $\begin{array}{l}.102 \\
0.034\end{array}$ & $\begin{array}{l}.161 \\
0.033\end{array}$ & $\begin{array}{l}.949 \\
0.008\end{array}$ \\
\hline Employment & $\begin{array}{r}.379 \\
0.185\end{array}$ & $\begin{array}{r}.448 \\
0.157\end{array}$ & $\begin{array}{c}.920 \\
0.240\end{array}$ \\
\hline Minority Stressors & $<.001$ & $<.001$ & 0.004 \\
\hline Everyday Discrimination & 0.021 & 0.030 & -0.032 \\
\hline Outness & $\begin{array}{l}.583 \\
0.067\end{array}$ & $\begin{array}{l}.481 \\
0.023\end{array}$ & $\begin{array}{l}.710 \\
0.068\end{array}$ \\
\hline Rejection Anticipation & $\begin{array}{c}.084 \\
-0.095\end{array}$ & $\begin{array}{c}.591 \\
-0.102\end{array}$ & $\begin{array}{c}.423 \\
-0.066\end{array}$ \\
\hline Identity Concealment & $\begin{array}{l}.013 \\
0.024\end{array}$ & $\begin{array}{l}.018 \\
0.029\end{array}$ & $\begin{array}{c}.444 \\
-0.015\end{array}$ \\
\hline Internal Homophobia & $\begin{array}{c}.526 \\
0.073\end{array}$ & $\begin{array}{c}.497 \\
0.005\end{array}$ & $\begin{array}{c}.864 \\
0.129\end{array}$ \\
\hline ACEs & $\begin{array}{c}.058 \\
0.054\end{array}$ & $\begin{array}{c}.900 \\
0.054\end{array}$ & $\begin{array}{r}.129 \\
0.082\end{array}$ \\
\hline Depressive symptoms & $\begin{array}{l}.183 \\
0.018\end{array}$ & $\begin{array}{c}.232 \\
-0.032\end{array}$ & $\begin{array}{l}.378 \\
0.199\end{array}$ \\
\hline Social support & $\begin{array}{c}.643 \\
-0.050\end{array}$ & $\begin{array}{c}.459 \\
-0.046\end{array}$ & $\begin{array}{c}.019 \\
-0.051\end{array}$ \\
\hline Resilience & $\begin{array}{l}.190 \\
0.013\end{array}$ & $\begin{array}{l}.291 \\
0.024\end{array}$ & $\begin{array}{c}.550 \\
-0.013\end{array}$ \\
\hline & .723 & .575 & .882 \\
\hline
\end{tabular}

\section{Figures}




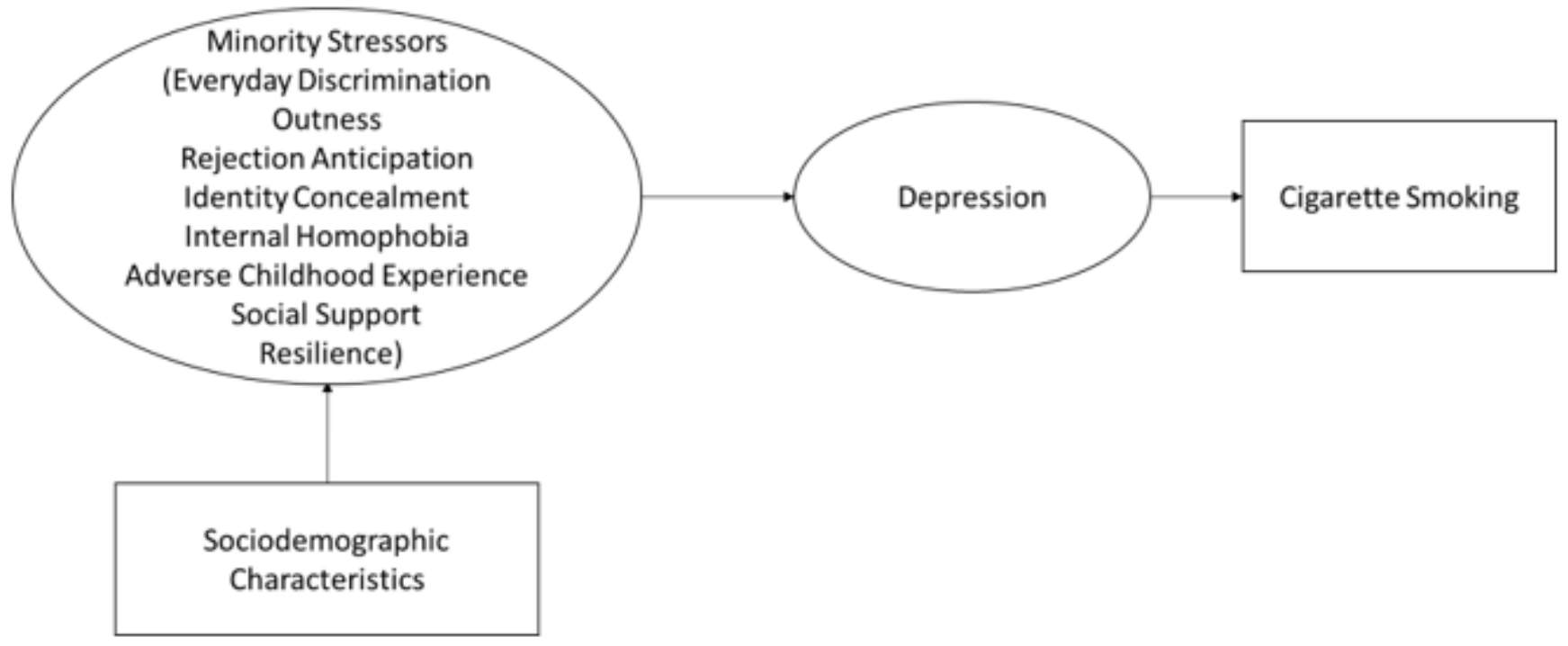

\section{Figure 1}

Hypothesized conceptual model of minority stressor to cigarette smoking among gay and bisexual men in China

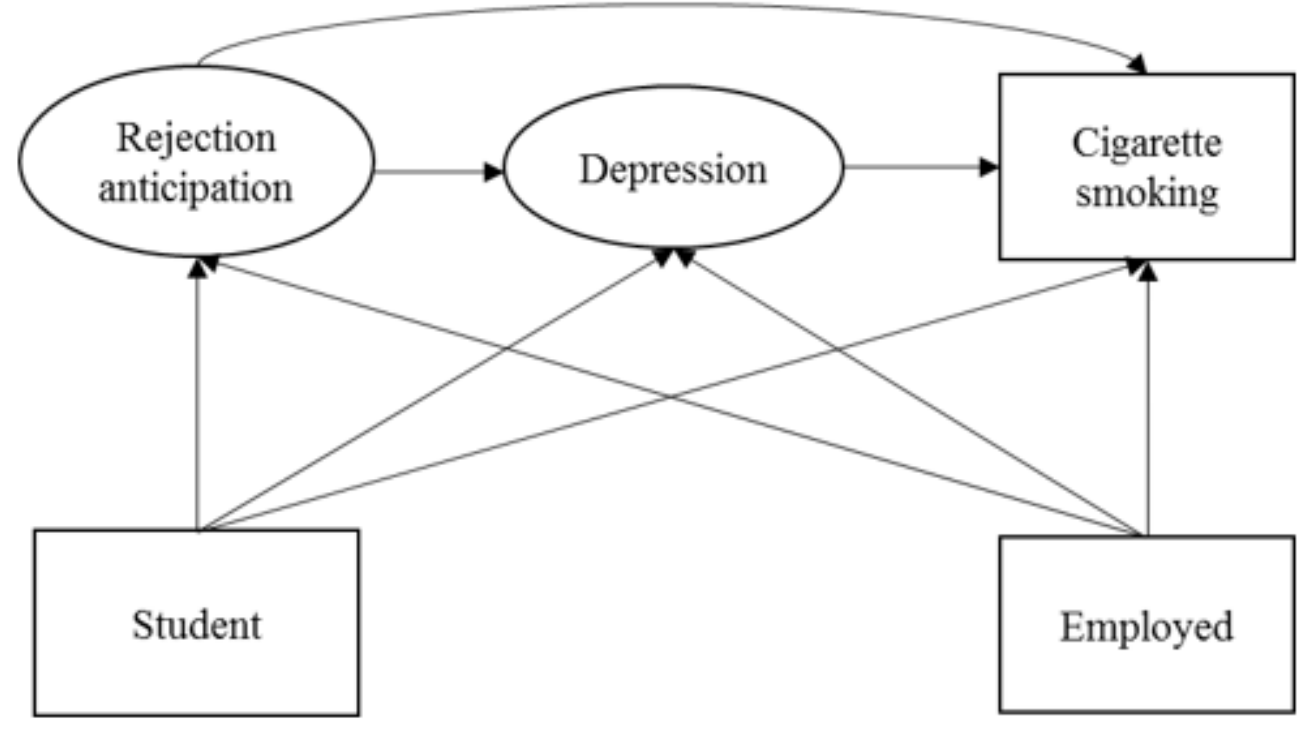

Figure 2

Specified two-group structural equation model of rejection anticipation to cigarette smoking for both gay and bisexual men in China 
$-0.15^{* *}$

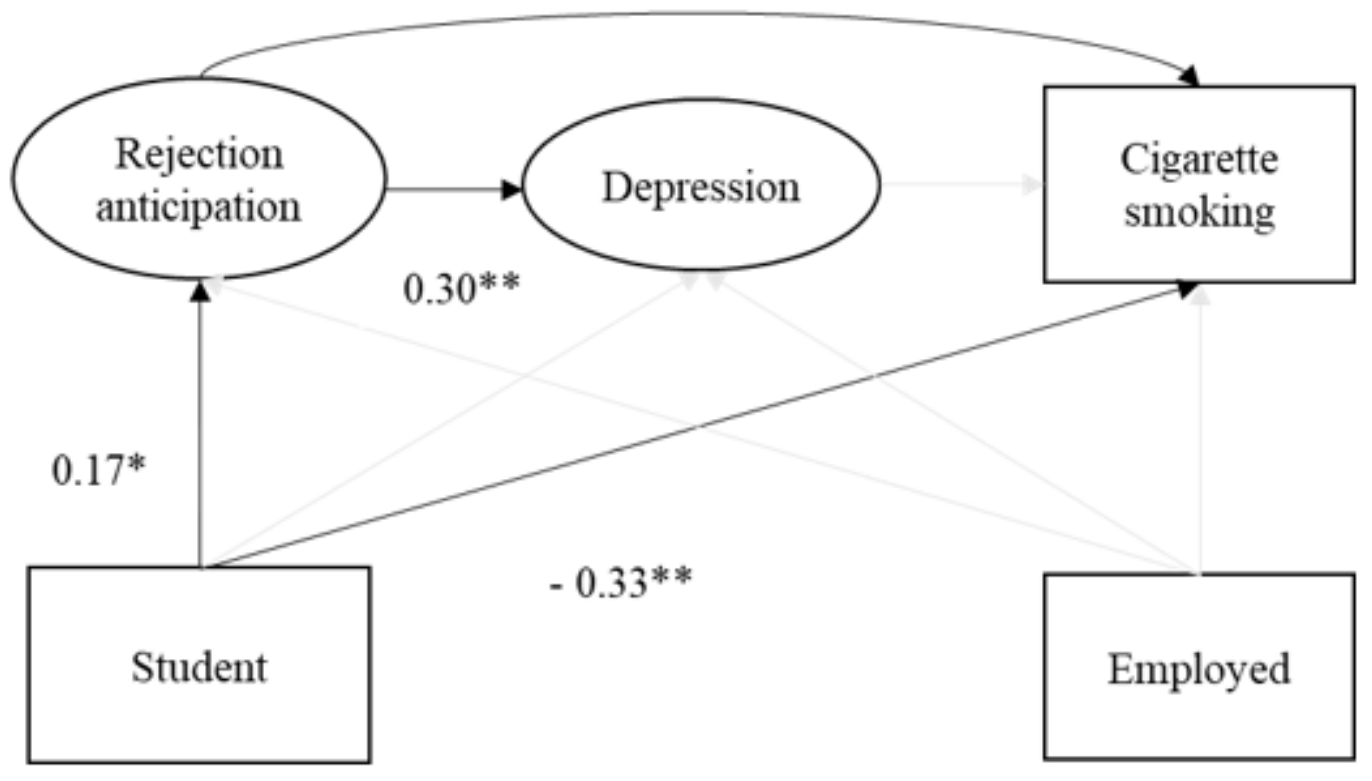

${ }^{*} p<0.05, * * p<0.001$

\section{Figure 3}

Final structural equation model testing pathway between rejection anticipation, depressive symptoms, and cigarette smoking among Chinese gay men and bisexual men. Model fit: $\chi 2=981.28, d f=770$, $p<0.001$ (recommended p>0.05); RMSEA: 0.028 (recommended <0.05); CFI: 0.920 (recommended >0.90); TLI: 0.916 (recommended >0.90); WRMR = 1.397 (recommended < 1). Coefficients: Rejection anticipation was positively associated with greater depressive symptoms (standardized $\beta=0.30, p<.001$ ) and negatively associated with being a current cigarette smoker (standardized $\beta=-0.15, p<.001$ ). Being a student was positively associated with higher rejection anticipation (standardized $\beta=0.17, p<.05$ ) and was negatively associated with cigarette smoking (standardized $\beta=-0.33, p<.05$ ). Being a student was not associated with depressive symptoms. Depressive symptoms not associated with cigarette smoking. 